NBSIR 85-3130

\title{
A Model Describing the Steady-State Pyrolysis of Bubble-Forming Polymers in Response to an Incident Heat Flux
}

I. S. Wichman

U.S. DEPARTMENT OF COMMERCE

National Bureau of Standards

National Engineering Laboratory

Center for Fire Research

Gaithersburg, MD 20899

May 1985

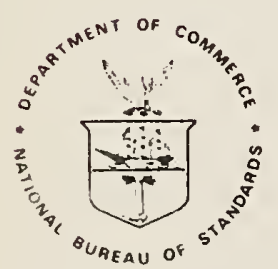

U.S. DEPARTMENT OF COMMERCE

$-Q 0$ ONAL BUREAU OF STANDARDS 



\section{A MODEL DESCRIBING THE STEADY-STATE PYROLYSIS OF BUBBLE-FORMING POLYMERS IN RESPONSE TO AN INCIDENT HEAT FLUX}

I. S. Wichman

U.S. DEPARTMENT OF COMMERCE National Bureau of Standards National Engineering Laboratory

Center for Fire Research

Gaithersburg, MD 20899

May 1985

U.S. DEPARTMENT OF COMMERCE, Malcolm Baldrigo, Secretary NATIONAL BUREAU OF STANDAADS. Emeat Ambler, Director 

LIST OF FIGURES $\ldots \ldots \ldots \ldots \ldots \ldots \ldots \ldots \ldots \ldots \ldots \ldots \ldots \ldots \ldots \ldots \ldots \ldots \ldots \ldots$

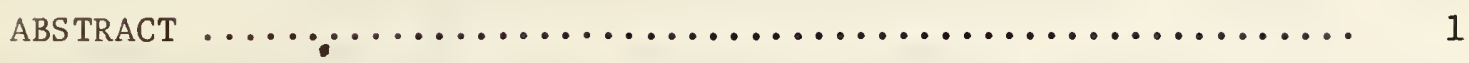

I. INTRODUCTION $\ldots \ldots \ldots \ldots \ldots \ldots \ldots \ldots \ldots \ldots \ldots \ldots \ldots \ldots \ldots \ldots$

II. GROWTH RATES AND TRANSLATIONAL VELOCITIES
FOR SINGLE BUBBLES $\ldots \ldots \ldots \ldots \ldots \ldots \ldots \ldots \ldots \ldots \ldots \ldots \ldots \ldots \ldots \ldots$

II. 1 The Translational Velocity ................. 6

II. 2 Growth Rate .......................... 8

ili. THE BUbBLE distribution function $\ldots \ldots \ldots \ldots \ldots \ldots \ldots \ldots \ldots \ldots$

III. 1 Solution for the Bubble Distribution Function .... 14

IV. CONSERVAtion Equations in THE MOLTEN POLYMER .......... 15

IV. 1 Conservation of Mass .................. 16

IV. 2 Conservation of Momentum .............. 17

IV. 3 Conservation of Species ................. 18

IV. 4 Conservation of Energy $\ldots \ldots \ldots \ldots \ldots \ldots \ldots \ldots \ldots$

IV. 5 Nondimensional Equations ................ 20

V. THE CASE OF NEARLY-CONSTANT POLYMER MASS FRACTION ....... 24

V. 1 Regression-Rate Formula .................. 29

IV. DISCUSSION AND CONCLUSIONS $\ldots \ldots \ldots \ldots \ldots \ldots \ldots \ldots \ldots \ldots \ldots \ldots$

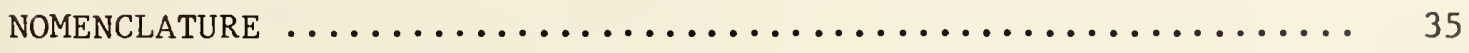

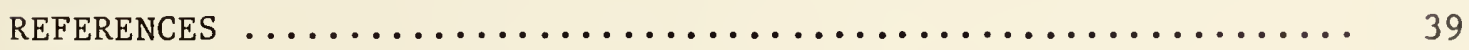


Figure 1. The model configuration $\ldots \ldots \ldots \ldots \ldots \ldots \ldots \ldots \ldots \ldots \ldots \ldots \ldots \ldots \ldots \ldots$

Figure 2. The nucleation and growth of bubbles in the polymer melt.

(a) Small clusters of monomer are formed. (b) The monomer clusters may nucleate small bubbles, which may grow or collapse. (c) The growing bubbles translate in the direction of the local temperature gradient; they are at all times surrounded by a layer of monomer. Bubble growth takes place through vaporization at the interface ... 42

Figure 3. Energy balance at the surface $\ldots \ldots \ldots \ldots \ldots \ldots \ldots \ldots \ldots \ldots \ldots \ldots \ldots$ 


\section{ABSTRACT}

A theoretical model is developed to describe the in-depth effect of bubbles on the steady-state transport of volatile gases (monomer) from the surface of a polymer subjected to an incident heat flux. In this model the effect of the bubbles on the surrounding (liquid) polymer is felt through the bubble number distribution function, $n$, which appears in the equations for conservation of mass, momentum, species and energy in the melt. The equation for the evolution of $n$ includes the effects of bubble growth, convection and nucleation; its derivation requires preliminary study of the growth and motion of an Individual bubble in a liquid with a temperature gradient. With these equations, formulas for the mass flux of volatiles from the polymer surface and the bubble void fraction are developed, for the special case of constant polymer mass fraction. 



\section{INTRODUCTION}

Although the regression and degradation of thermoplastic materials in response to external heating has been extensively studied [1-4], none of the previous models consider the influence of the in-depth mass-transfer process on the steady-state regression rate. In all of these models the heated condensate is assumed to remain solid until it finally gasifies at the surface, even though degradation reactions for the thermoplastic are included in the formulation. Consequently these models describe only the thermal and chemical mechanisms of polymer gasification.

However, recent experimental study of the gasification of thermoplastics [5] indicates that the rate of volatile gas evolution from the heated surface of the regressing polymer depends very strongly on physical processes occurring inside the heated material. Specifically, polymers such as polyethylene (PE) and polymethylmethacrylate (PMMA) are observed to liquify (with negligible thermal expansion) in response to an incident external heat flux, thereby allowing the nucleation of bubbles that grow and transport volatile gases (monomer) to the surface by moving through the molten layer. These indepth processes allow a substantial increase of the regression rate over that obtained when gasification occurs merely by surface vaporization.

The model configuration studied here is shown schematically in Fig. 1 . The incident heat flux, Q, through the gas causes the surface of the infinitely thick non-char-forming polymer to attain the temperature $\mathrm{T}_{\mathrm{S}}$ and to regress at a steady rate $r$. An increase of the heat flux generally 1ncreases both $\mathrm{T}_{\mathrm{s}}$ and $\mathrm{r}$. In Fig. 1 the coordinate system is fixed to the regressing 
surface. The incident heat flux initiates the thermal degradation reaction $P+M\left(\right.$ polymer + monomer) at some point, $x<\delta_{b}$, in the solid, thereby enabling the formation of small localized clusters of monomer. At the position $x=\delta_{b}$ (see Fig. 1), the saturation (boiling) temperature of the monomer is attained $\left(\mathrm{T}_{\mathrm{b}} \sim 100^{\circ} \mathrm{C}\right.$ for the monomer, MMA, of PMMA [5]). Since a significant quantity of undegraded (or on 1y partially degraded) polymer still exists at the surface [6], the surface temperature, $T_{S}$, attains values much greater than the saturation temperature of the liquid monomer, $\mathrm{T}_{\mathrm{b}}$.

Therefore, as the surface is approached the local temperature rises well above the monomer superheat limit and homogeneous nucleation of bubbles in the monomer clusters in $x>\delta_{b}$ occurs spontaneously (note that heterogeneous nucleation may occur at sites of chemical impurity, at inclusions, etc. throughout the heated polymer), see Fig. 2. Consequently the degree of superheating and the bubble nucleation rate both increase while the viscosity and surface tension of the liquid (the principal obstacles to bubble growth in the early stages) both decrease. The nucleated bubbles then grow by monomer vaporization, thermal expansion and collisions with other bubbles, and finally release their contents to the gas at $x=0$.

The practical importance of the configuration shown in Fig. 1 is its fundamental similarity to that occurring in laboratory-scale flame spread across thermally-thick polymers. In these problems the heat flux, Q, is supplied by the exothermic reaction at the gas-phase flame; the fuel for the flame is in turn supplied by the release of volatiles from the polymer surface. Clearly, the rate of volatiles release affects the flame spread 
rate. The actual flame-spread configuration differs from that of Fig. 1 because Q (which normally is a combination of conductive and radiative heat fluxes to the surface) varies with the downstream distance from the flame front (since the distance between the flame and the surface changes). Consequently, the one-dimensional configuration of Fig. 1 is only locally valid.

In the following section expressions for the growth rate and translational velocity of an individual bubble in a variable-property viscoelastic medium are derived. These expressions for an individual bubble are then used in Section III to derive an equation for the evolution of the bubble number distribution function, which describes the influences of convection and bubble nucleation on the changes in the bubble distribution in the molten polymer. Section IV then discusses the influence of the bubble distribution on the fluid-dynamical behavior of the polymer melt (the bubble distribution function enters the conservation equations for the molten polymer through the source and sink terms contained therein; for example, the overall effect of the bubbles on the equation for conservation of mass is to produce a mass sink). An analytical solution for the special case of constant polymer mass fraction is then presented in Section $V$.

\section{GROWTH RATES AND TRANSLATIONAL VELOCITIES FOR SINGLE BUBBLES}

Before proceeding to a detalled discussion of the effects of the bubble distribution on the regression rate, the behavior of an individual bubble in a viscoelastic medium must be satisfactorily described. A spherical bubble generally has two components of motion, translational and radial. Expressions 
for the translational velocity $\underset{\sim}{v}$ and the radial growth rate $k$ are obtained herein from the extensive review literature concerned with the flow of fluld particles through viscous media [7-9] and with bubble dynamics [10-14], respectively. In the 11terature these two components of motion are examined independently; thus, analyses of fluid-particle flow through viscous media focus on the fluid-mechanical description of the flow fields inside and around fluid particles of fixed shape, while the literature of bubble dynamics deals only with bubble growth, usually in spherically-symmetric flow fields. Some modifications of these previous calculations will clearly be necessary here, since the bubble translational motion and growth rate, in a liquid with a temperature gradient, are actually coupled.

\section{1 The Translational Velocity}

It has been experimentally observed that small bubbles move in the direction of the local liquid temperature gradient. This motion occurs because of the stresses induced by the gradient of the surface tension. A local increase in the surface temperature produces a local decrease of the surface free energy (the surface tension), $\sigma$, which generates a non-uniform tangential stress in the surface, in a direction opposite to the temperature gradient. Therefore, the direction of the surface flow in the bubble is away from the warmer pole and toward the cooler pole, so that the bubble moves in the direction of its warmer pole with respect to the liquid.

An analytical expression for the translational velocity of the bubble is obtained by examining the steady-state, low-Reynolds-number limit of the Navier-Stokes equations. In addition, the local temperature gradient is 
assumed linear, the local fluid viscosity is assumed constant ${ }^{*}$ and the variation of the surface tension is assumed linear in the temperature gradient, viz., $\underset{\sim}{\nabla \sigma}=(\mathrm{d} \sigma / \mathrm{dT}) \underset{\sim}{\nabla T}$. The condition of axial symmetry can be applied when the gravitational vector and the temperature gradient are parallel. Thus [9],

$$
v(x, R)=\frac{g R^{2}}{3 \nu}+\frac{R}{2 \mu}\left(-\frac{d \sigma}{d T}\right) \frac{d T}{d x},
$$

where $\mathrm{x}$ is the direction of motion, $\mathrm{g}$ is the gravitational constant, $\mathrm{R}$ is the bubble radius and $\nu=\mu / \rho$ is the kinematic viscosity of the liquid. For small bubbles the buoyancy-induced component of the translational velocity, $g R^{2} / 3 \nu$, may be neglected in comparison with the thermal-gradient component. By nondimensionalizing $\mathrm{Eq} .(2.1)$ and then dividing the respective nondimensional groups, one finds that this condition is satisfied when

$$
E_{0} \equiv \frac{\rho_{0} g D_{0}^{2}}{\sigma_{0}} \ll 0\left(\frac{R_{0}}{L_{0}}\right) .
$$

Here $E_{o}$ is the Eötvös number, $L_{o}$ is the characteristic conduction length for large changes in the temperature gradient and $D_{0}=2 R_{0}$ is the characteristic bubble diameter. For small bubbles in molten PMMA, reasonable estimates are $\rho_{0} \sim 1 \mathrm{~g} / \mathrm{cm}^{3}, \mathrm{R}_{0} \sim 10^{-2} \mathrm{~cm}, \mathrm{~L}_{\mathrm{o}} \sim 10^{-1} \mathrm{~cm}$ and $\sigma_{\mathrm{o}} \sim 20 \mathrm{dyne} / \mathrm{cm}$, which gives $\mathrm{E}_{\mathrm{O}} \sim 10^{-2}$ and $\mathrm{R}_{\mathrm{o}} / \mathrm{L}_{\mathrm{o}} \sim 10^{-1}$, thereby satisfying the conditions of $\mathrm{Eq} \cdot(2.2)$. Therefore, the expression for $\underset{\sim}{v}$ used henceforth is

$$
\underset{\sim}{v}(\underset{\sim}{x}, R)=\frac{R}{2 \mu(x)}\left(-\frac{d \sigma}{d T}\right) \underset{\sim}{\nabla T} \equiv \underset{\sim}{J}(\underset{\sim}{x}) R,
$$

\footnotetext{
*Viscosity gradients cannot, by themselves, exert forces on the bubbles. Therefore the assumption of constant viscosity does not have a significant effect on the subsequent formulas for $v$.
} 
where the variation of $\mu$ with position $\underset{\sim}{x}$ has been included. Note from Eq. (2.3) that $|\underset{\sim}{v}|$ increases when $R$ and $|\underset{\sim}{\nabla T}|$ increase and when $\mu$ decreases; the bubbles accelerate as the surface is approached.

\section{2 Growth Rate}

There are many possible expressions for $\dot{R}(x, R)$, depending on whether the particular growth regime under consideration is dominated by viscous, inertial or thermal effects [11-14]. Bubble growth rates also depend on additional factors such as the concentration of dissolved gases in the liquid [15], its viscoelastic behavior [16] (i.e., whether or not it is Newtonian) and whether it is a single-component fluid or an emulsion [17]. In this study it is assumed that the liquid polymer is a single-component Newtonian fluid containing no dissolved gases. When the conditions of spherical symmetry apply, the equilibrium radius of a vapor bubble that has nucleated in such a medium is

$$
R=2 \sigma /\left[p_{v}(T)-p\right]
$$

where $\mathrm{p}_{\mathrm{v}}$ is the bubble vapor pressure and $\mathrm{p}$ is the ambient liquid pressure $\left(p=p_{0}-p(\underset{\sim}{g} \cdot \underset{\sim}{x})\right.$ for the regressing surface, where $p_{0}$ is the gas pressure at the surface, see Fig. 1). In Eq. (2.4) the surrounding liquid temperature T must be greater than the bubble vapor temperature $\mathrm{T}_{\mathrm{v}^{*}}$ The quantity $\Delta \mathrm{T} \equiv \mathrm{T}-\mathrm{T}$ v is called the liquid superheat.

After the bubble has nucleated, the primary obstacle to radial growth in this initial growth stage is the opposing action of the surface tension. In 
this stage $\mathrm{p}_{\mathrm{v}} \gg \mathrm{p}$, so that Eq. (2.4) gives $\mathrm{R} \sim 2 \sigma / \mathrm{p}_{\mathrm{v}}$; assuming $\mathrm{p}_{\mathrm{v}} \geqslant 10$ atm and $\sigma \sim 20$ dyne/cm gives $R \lesssim 0\left(10^{-6} \mathrm{~cm}\right)$. The next stage of bubble growth is controlled by liquid inertia. This stage is followed by an intermediate growth stage in which both inertial and thermal effects dominate*; a continuous influx of thermal energy is required to provide the additional vapor for bubble growth. In these stages of growth the surface tension term in Eq. (2.4) is $O(1)$; using $\mathrm{P}_{\mathrm{V}} \gtrsim 1$ atm gives $2 \mathrm{R} \lesssim 10^{-4} \mathrm{~cm}$. Finally thermal effects alone control the growth process. In this final stage numerous authors [18-20] have shown that

$$
\dot{R}=\sqrt{3 / \pi}\left[\lambda / \rho_{\mathrm{v}} \mathscr{L}\right] \Delta \mathrm{T} / \sqrt{\alpha \mathrm{t}},
$$

where $\mathcal{L}$ and $\alpha$ are the latent heat of vaporization and the thermal diffusivity of the liquid, respectively. Thus, $R$ is obtained as an approximate balance between the rate of heat flow into the bubble from the liquid, $4 \pi R^{2} \lambda \Delta T / \sqrt{a t}$, and the latent heat required to supply the vapor in the bubble $[14], 4 \pi R^{2} \mathcal{L}_{\rho}{ }_{v}$. In this final growth stage the surface-tension term in Eq. (2.4) becomes negligibly sma11; therefore $2 \mathrm{R} \gg 10^{-4} \mathrm{~cm}$.

Obtaining simple analytical expressions for $k$ analogous to Eq. (2.5) in the inertia-controlled and the thermal/inertia-controlled growth stages is generally not possible because the governing equations of motion are nonlinear. ${ }^{\dagger}$ But since the average bubble radius in its inftial growth stages, $\mathrm{R}_{I}$, is at least one to two orders of magnitude smaller than in the final

\footnotetext{
*Diffusional effects need not be considered because the bubble is assumed always to be surrounded by a thin layer of liquid monomer (see Fig. 2).

${ }^{\dagger}$ A simple interpolation formula for $R(t)$ has been suggested [21]. However, the physical grounds for deriving this formula are weak.
} 
(therma1) growth stage, $R_{T}$ (1.e., $R_{I} / R_{T} \lesssim 10^{-1}$ ), 1ts overall effect on the transport of mass and momentum in the mixture is smaller by a factor of at least $10^{-3}$ for mass transport (since $\rho_{v} v \propto R^{3}$ ) and at least $10^{-4}$ for momentum transport (since $\rho_{v} V v \propto R^{4}$ ). Consequently the detailed modeling of bubble growth in the smal1-R regimes appears unnecessary, and Eq. (2.5) is believed sufficient.

The integration of Eq. (2.5) with respect to $t$ gives $R \propto t^{1 / 2}$; thus

$$
\dot{R}(\underset{\sim}{x}, R)=\frac{K(\underset{\sim}{x})}{R},
$$

where $\mathrm{K} \underset{\sim}{\mathrm{x}})=(6 / \pi) \alpha\left(\rho / \rho_{\mathrm{v}}\right)^{2}\left(c_{\mathrm{p}} \Delta \mathrm{T} / \mathcal{L}\right)^{2}=(6 / \pi) \alpha \Lambda^{2}$ is now considered a function of position because of the changes encountered in $\rho, \rho_{v}, c_{p}, \lambda, \Delta \mathrm{T}$ and $\mathcal{L}$ as the bubble translates through the 11quid. Here $\Lambda \equiv\left(\rho / \rho_{v}\right)\left(c_{p} \Delta T / \mathcal{C}\right)$ is the Jakob number. Note that the effects of property changes on $k$, arising from the bubble motion, can also be accounted for by replacing $K(\underset{\sim}{x})$ by $K[1+\varepsilon(\underset{\sim}{x})]$, where $\mathrm{K}$ is now constant and $\varepsilon$, the correction factor, must be obtained empirically. By analogy with droplet flows in sprays [22], $\varepsilon \sim \operatorname{Re}^{\mathrm{m}} \operatorname{Pr}^{\mathrm{n}}$, where $\operatorname{Re}=2 \mathrm{vR} / \nu$ is the Reynolds number and $\operatorname{Pr}=\nu / \alpha$ is the Prandt 1 number. Other forms for $\varepsilon$ are, of course, also possible.

\section{THE BUBBLE DISTRIBUTION FUNCTION}

The calculations of the preceding section are now extended to derive, physically, a statistical equation for the evolution of the bubble number distribution function; this equation will subsequently be used to describe the overall influence of the bubbles on the pyrolysis process. To provide such a 
statistical description it is necessary to specify the number distribution function, $n(\underset{\sim}{x}, V, t) d \underset{\sim}{x} d V$, which gives the probable number of bubbles in the volume range $d V$ of $V$ and in the coordinate range $\underset{\sim}{x}$ of $\underset{\sim}{x}$ at time $t_{\cdot}^{*}$ Before deriving the evolution equation for $n$, however, various physical assumptions relevant to the configuration of $\mathrm{F} 1 \mathrm{~g}$. 1 must be stated and discussed.

It is assumed here that the bubbles are spherical $\left[\mathrm{V}=(4 / 3) \pi R^{3}\right]$, that the surface-regression process is steady-state and one-dimensional (1.e., $\partial(\cdot) / \partial t=0$ and $\underset{\sim}{\nabla} \cdot(\cdot)=\partial(\cdot) / \partial x$ etc. $)$, that the effects of bubble breakup are negligible and that the rate of binary bubble collisions is negligible. These assumptions are now discussed in turn.

The bubbles will be spherical when the Reynolds number for the flow around each rising bubble, $R e=2 R_{0} v_{0} / \nu_{0}$, is small compared with unity, regardless of the values of the Eötvös number, [Eq. (2.2)], and the Morton number, $M=g \mu_{0}^{4} / \rho_{0} \sigma_{0}^{3}[7]$. For PMMA reasonable values of $\nu_{0}, R_{0}$ and $v_{0}$ are $\nu_{0} \sim 10 \mathrm{~cm}^{2} / \mathrm{s}, 2 \mathrm{R}_{0} \leqslant 10^{-1} \mathrm{~cm}$ and $v_{0} \sim 10^{-2} \mathrm{~cm} / \mathrm{s}$, whereby $\mathrm{Re} \lesssim 10^{-4}$; therefore these bubbles will always be spherical.

Surface regression occurs as a steady-state process when the thickness, $\tau$, of the condensed-phase sample is much greater than the thermal wave penetration depth, $L_{s}=\lambda / \rho c_{p} r$. The steady-state regression of PMMA and PE samples can only be achieved for very large heating times, $t \rightarrow \infty[5]$, when the incident heat flux is radiative. This occurs because these polymers are very nearly optically transparent to the short-wavelength near-infrared radiation

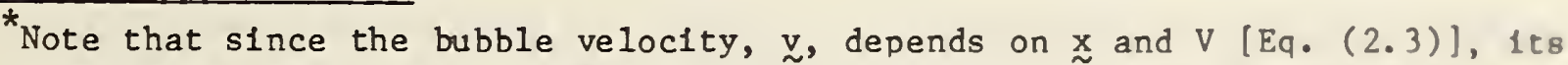
components cannot be considered as additional independent variables in $n$.
} 
used to heat the surface in these experiments; the radiant preheating continually increases the thermal wave penetration depth (and therefore the regression rate, r) unt11 the final (asymptot1c) value is attained [5].

The assumption of one-dimensionality corresponds physically to the neglect of temperature variations in the transverse $(y-z)$ plane compared with variations in the vertical coordinate, $x$ [see Fig. 1]. Therefore the sides of the sample must be insulated and the temperature perturbations caused by neighboring bubbles must be negligible. In this case probabilistic variations in the dependent variables (such as the bubble number distribution function, the 11quid density, pressure, velocity, enthalpy, etc...) and in the thermophysical and transport properties such as specific heats and thermal conductivities occur only in $x$.

For a stagnant liquid in which the large-scale effects of turbulence and velocity gradients are negligible the only remaining mechanism for bubble breakup is the growth of a Rayleigh-Taylor instability in the bubble surface [7]. For a translating bubble the leading surface becomes unstable when the wavelength of a disturbance there exceeds the critical value, $\lambda_{\text {crit }} \sqrt{\sigma_{0} / \rho_{0} g}$. The approximate criterion for stable disturbances is $\mathrm{E}_{0} \lesssim 16$. For PMMA $\rho_{0} \sim 1 \mathrm{~g} / \mathrm{cm}^{3}$ and $\sigma_{0} \sim 20$ dyne $/ \mathrm{cm}$, whereby $R_{0} \lesssim 0.3 \mathrm{~cm}$ for stability. This condition will always be satisfled in this study.

When the bubble number density is high and when many disparate bubble sizes are present the effect of collisions cannot be neglected. Under the conditions studied here one can write, by analogy with the theory of falling droplets [23], $\mathrm{K}_{C} \simeq \pi\left(\mathrm{R}_{1}+\mathrm{R}_{2}\right)^{2}\left[\mathrm{v}_{1}-\mathrm{v}_{2}\right]$ for the bubble collision frequency 
factor, where $R_{1}$ and $v_{1}$ respectively, represent the radius and velocity of bubble 1. Note that $R_{1}>R_{2}$ is required here, since $v_{1} \sim R_{1}$ and $K_{C}>0$. Therefore when $R_{1}-R_{2} \ll O(1)$ the collision term becomes negligible. An alternative criterion for neglecting collisions is $R_{0} / L<<O(1)$, where $L$ is the average distance between bubbles. Defining $\mathrm{L} \sim\left(\mathrm{N}_{0}\right)^{-1 / 3}$, where $\mathrm{N}_{0}$ is a representative value of the bubble number density, and putting $R_{0} \sim 10^{-2} \mathrm{~cm}$ and $\mathrm{N}_{\mathrm{o}} \sim 10^{3}$ bubbles $/ \mathrm{cm}^{3}$ gives $\mathrm{R}_{\mathrm{o}} / \mathrm{L} \sim 10^{-1} \ll \mathrm{O}(1)$; thus the bubble distribution must be disperse.

Under these assumptions the equation for the evolution of the bubble distribution function becomes

$$
\frac{\partial(n \dot{R})}{\partial R}+\frac{\partial(n v)}{\partial x}=0
$$

where the terms $\partial(n R) / \partial R$ and $\partial(n v) / \partial x$ represent the flux of $n$ through $R-s p a c e$ and physical space, respectively. Note that $\mathrm{n}$ is now considered to be a function of $x$ and $R$. Note also that Eq. (3.1) can be derived by taking the derivative, with respect to $R$, of the more-general integral equation

$$
(n \dot{R})_{R}+\frac{\partial}{\partial x} \int_{R^{*}}^{R} n(x, s) v(x, s) d s=(n k)_{R^{*}} \text {, }
$$

where the term on the right-hand side represents the nucleation rate. Here, $R^{*}$ is the critical cluster size for nucleation, which is two to three orders of magnitude smaller than the smallest macroscopic bubble shown in Fig. 1. Since Eq. (3.2), as written, is quite general, any of the numerous forms for $(n k)_{R *}$ derived in the extensive review literature of nucleation theory can be used [24-26]. In this study, however, a simple expression (obtained from the so-called classical theory of nucleation) is employed. 
In this theory the nucleation process is modeled as a kinetic mechanism, which takes place through the stepwise agglomeration process, $A_{j}^{*}+A_{1}+A_{j+1}^{*}$, where $A_{j}^{*}$ represents an activated cluster of $f$ single monomer molecules and $A_{1}$ is an unactivated monomer molecule. Therefore, $(n k)_{R *}$ is equal to the product of the equilibrium concentration of critical clusters, $F \cdot \exp \left[-4 \pi \sigma R *^{2} / 3 k T\right]$, with the characteristic pre-exponential rate constant, $\sqrt{2 \sigma / \pi \mathrm{m}}, \mathrm{viz} \cdot[27,28]$,

$$
\begin{aligned}
(n \dot{R})_{R^{*}} & =F \cdot \sqrt{2 \sigma / \pi m} e^{-\frac{4 \pi \sigma k^{2}}{3 k T}} \\
& \equiv C(x) e^{-H(x) / T(x)} .
\end{aligned}
$$

Here, $F$ is the number of liquid molecules per unit volume of the original liquid, $\sigma$ is the surface tension, $k$ is the Boltzmann constant and $m$ is the average molecular mass. The pre-exponential factor, $\mathrm{C}(\mathrm{x})$, becomes vanishingly small for large, negative $x$ (see Fig. 1), because F $\rightarrow 0$ there. Simllarly, the exponential factor becomes small when $R^{*} \gg \sqrt{3 k T / 4 \pi \sigma}$; for PMMA this condition is satisfied (using $\sigma \sim 20$ dynes/cm, $\mathrm{k} \sim 1.4 \times 10^{-16} \mathrm{erg} /{ }^{\circ} \mathrm{K}$ and $\mathrm{T} \sim 10^{3}{ }^{\circ} \mathrm{K}$ ) when $R^{*} \gg 10^{-7} \mathrm{~cm}$.

\section{1 Solution for the Bubble Distribution Function}

Equation (3.1) can be solved, with the aid of Eqs. (2.3), (2.6) and (3.3), to give

$$
n(x, R)=\frac{R}{K(z)} \frac{J(z)}{J(x)} C(z) e^{-H(z) / T(z)},
$$

where the variable $z$ is defined by the equation 


$$
1-\frac{3}{R^{3}} \int_{z}^{x} \frac{K(s)}{J(s)} d s=\frac{R}{R}^{3}
$$

Note that the condition $C(-\infty)=0$ gives $11 m n(x, R)=0$ and $11 m n(x, R)=0$.

$$
x+\infty \quad R+\infty
$$

When $\mathrm{K} / \mathrm{J}$ in Eq. (3.5) is constant, then the varlable $\mathrm{z}$ takes the simple form

$$
\mathrm{z} \doteq \mathrm{x}-\left(\frac{\mathrm{J}}{3 \mathrm{~K}}\right) \mathrm{R}^{3}
$$

obtained from Eq. (3.5) by taking the $11 \mathrm{mit} R * / R \rightarrow 0$. In spite of this simplification, however, the effect of the bubble number distribution on the conservation of mass, momentum, species and energy in the polymer melt [which enters Eqs. (4.3), (4.7), (4.11) and (4.12) through 1ntegrals over R] is st111 very complicated, since $n$ contains the dependent variable $T(z)$ in the exponent.

IV. CONSERVATION EQUATIONS IN THE MOLTEN POLYMER

Equation (3.4) is coupled to the conservation equations for the molten polymer through the various sink terms, which describe, in an average sense, the effect of the bubble distribution on the loss of mass, momentum, species and energy from the liquid to the bubbles. In what follows it is shown that the usual equations of fluid dynamics describe the changes in the average liquid propertles, provided that the proper source terms are added to account for the average effect of the bubbles. * The preclse form of the source terms

\footnotetext{
${ }^{*}$ A rigorous evaluation of the effect of the source terms on the 11quid properties would Involve application of the boundary conditions at each bubble and then the computation of an ensemble average [22]. Th1s procedure 1s, for this study, unnecessarily complex.
} 
used here can be deduced from the equations for conservation of mass, momentum and energy in the vapor-phase component of the two-phase mixture. These equations are obtained by multiplying Eq. (3.1) by $\rho_{\mathrm{v}} \mathrm{V}, \rho_{\mathrm{v}} \mathrm{Vv}$ and $\rho_{v} V\left(h_{v}+v^{2} / 2\right)$, the mass, momentum and energy, respectively, of a single vapor bubble of volume $V=(4 / 3) \pi R^{3}$ and density $\rho_{v}$, and then Integrating over $R$. A1though the detalls of this calculation are not pursued here, it is stralghtforward to show that the source terms arising in the vapor-phase equations are identical to the sink terms appearing in the corresponding conservation equations for the liquid [on the right-hand sides of Eqs. (4.3), (4.7) and (4.12)]. Instead, the derivation presented here is phenomenologica1.

\section{1 Conservation of Mass}

The loss of mass from the liquid to a bubble of density $\rho_{v}(x)^{\dagger}$ and volume $V=(4 / 3) \pi R^{3}$ is $-d\left(\rho_{v} V\right) / d t$; therefore for a11 bubbles the mass loss from the liquid is

$$
-\int_{0}^{\infty} n \frac{d\left(\rho_{v} V\right)}{d t} d R,
$$

where $n=n(x, R)$ and

$$
\frac{d(\cdot)}{d t}=\dot{R} \frac{\partial(\cdot)}{\partial R}+v \frac{\partial(\cdot)}{\partial x}
$$

\footnotetext{
$\dagger_{\text {The vapor density } \rho_{\mathrm{y}}}$ is given by $\rho_{\mathrm{v}}=\mathrm{p}_{\mathrm{v}} / \Omega \mathrm{T}_{\mathrm{v}}$, where $\mathrm{T}_{\mathrm{v}}=\mathrm{T}_{\mathrm{v}}(\mathrm{x})$ [13]. From $\mathrm{Eq} .(2.4), \mathrm{p}_{\mathrm{v}} \simeq \mathrm{p}$ since the surface-tension term is negligibly sma11. But $\mathrm{p}=\mathrm{p}_{0}-\rho(\mathrm{g} \cdot \mathrm{x})$, where $\mathrm{p}_{0}$ is the pressure in the gas at $\mathrm{x}=0$. Thus $\rho_{\mathrm{v}}=\rho_{\mathrm{v}}(\mathrm{x})$. Note also that $\mathrm{d} \rho_{\mathrm{v}} / \mathrm{dx} \simeq-\rho_{\mathrm{v}} \mathrm{d}\left(\ln \mathrm{TT}_{\mathrm{v}}\right) / \mathrm{dx}$.
} 
The equation for conservation of mass for the liquid is then

$$
\frac{d\left(\rho_{f} u\right)}{d x}=-\int_{0}^{\infty} n \frac{d\left(\rho_{v} v\right)}{d t} d R
$$

where $u$ is the velocity of the liquid and $\rho_{f}$, the fluid density, is the mass of liquid per unit volume of physical space. Since the volume fraction of physical space occupied by the bubbles is $\int_{0}^{\infty} n(x, R) V d R$, the fluid density and the liquid density [the mass of liquid per unit volume of liquid] are related by

$$
\frac{\rho_{f}}{\rho}=1-\frac{4 \pi}{3} \int_{0}^{\infty} n(x, R) R^{3} d R=1-\frac{4 \pi}{3} \pi_{3}(x),
$$

where

$$
\Pi_{m}(x)=\int_{0}^{\infty} n(x, R) R^{m} d R
$$

is the $\mathrm{m}^{\text {th }}$ moment of the bubble distribution function. By using Eqs. (2.3), $(2.6),(4.2)$ and $(4.5), E q .(4.3)$ reduces to

$$
\frac{d}{d x}\left(\rho_{f} u\right)=-\left[4 \pi \rho_{v} K \Pi_{1}+\frac{4 \pi}{3} \frac{d \rho_{v}}{d x} J \Pi_{4}\right] \text {. }
$$

\section{2 Conservation of Momentum}

The equation for conservation of momentum is

$$
\frac{d}{d x}\left(\rho_{f} u^{2}+p+\tau_{x x}\right)=-\int_{0}^{\infty} \frac{n d\left(\rho_{v} V v\right)}{d t} d R=-\int_{0}^{\infty} n F d R,
$$


where the shear stress, $\tau_{\mathrm{xx}}$, for a Newtonian liquid with negligible bulk viscosity, is given by

$$
\tau_{\mathrm{xx}}=-\frac{4}{3} \mu \frac{\mathrm{du}}{\mathrm{dx}}
$$

and $F \equiv d\left(\rho_{v} V v\right) / d t$ represents the net force per unit mass exerted on the bubble by the fluid. In general, $F$ can be decomposed into the components $F_{D}$ and $F_{G}$, opposing bubble translation (i.e., $F_{D}=\rho_{v} V d v / d t$ is the drag force on the bubble) and bubble growth $\left(F_{G}=v d\left(\rho_{v} v\right) / d t\right)$. The drag force, $F_{D}$, on a bubble of radius $R$ and velocity $v(x, R)$ is given by [7]

$$
F_{D}(x, R)=-4 \pi \mu(x) R v(x, R)
$$

Therefore with the assistance of Eqs. (2.3), (2.6), (4.2), (4.5), (4.8) and (4.9), Eq. (4.7) becomes

$$
\frac{d}{d x}\left(\rho_{f} u^{2}+p-\frac{4}{3} \mu \frac{d u}{d x}\right)=4 \pi \mu J \pi_{2}-J\left[4 \pi \rho_{v} K_{2}+\frac{4 \pi}{3} \frac{d \rho v}{d x} J \pi_{5}\right] .
$$

\section{3 Conservation of Species}

With Eqs. (4.3) and (4.6) as guides, one writes

$$
\begin{aligned}
\frac{d}{d x}\left[\rho_{f}\left(u+U_{k}\right) Y_{k}\right] & =w_{k}-\Omega_{k} \int_{0}^{\infty} n \frac{d\left(\rho_{v} v\right)}{d t} d R, k=1, \ldots, M \\
& =w_{k}-\Omega_{k}\left[4 \pi \rho_{v} K_{1}+\frac{4 \pi}{3} \frac{d \rho_{v}}{d x} J_{4}\right], k=1, \ldots, M
\end{aligned}
$$


for the conservation equations of the $M$ polymer species. Here $Y_{k}, U_{k}, w_{k}$ and $\Omega_{k}$ are the mass fraction, the diffusion velocity, the rate of mass creation by chemical reaction, per unit volume, and the mass flux fraction across the bubble interface* of species $k$, respectively. Note that $\sum_{k} w_{k}=0$ and $\sum \Omega_{k}=1$; both the $w_{k}$ and the $\Omega_{k}$ are generally functions of position, $x$. IV. 4 Conservation of Energy

The loss of energy from the liquid to an Individual bubble is accounted for by the sink term $-d\left(\rho_{v} h_{v}+\rho_{v} V v^{2} / 2\right) / d t$, where $h_{v}=h_{v}^{(0)}+c_{p v}\left(T-T_{\infty}\right)$ is the bubble vapor enthalpy. Therefore the equation for conservation of energy for the liquid becomes

$$
\frac{d}{d x}\left[\rho_{f} u\left(h+\frac{u^{2}}{2}\right)+q+u \tau_{x x}\right]=-\int_{0}^{\infty} n \frac{d}{d t}\left[\rho_{v} h_{v}+\rho_{v} v \frac{v^{2}}{2}\right] d R
$$

where $h=h^{(0)}+c_{p}\left(T-T_{\infty}\right)=\sum_{k} h_{k} Y_{k}$ is the 1iquid enthalpy and $q=-\lambda d T / d x+\rho_{f} \sum_{k} h_{k} U_{k} Y_{k}$ is the heat flux. With these definitions of $h$ and $q$ and Eq. (4.8) for $\tau_{x x}$, Eqs. (4.3), (4.11) and (4.12) can be combined to produce an energy balance that includes the chemical reaction term, $\sum_{k} h_{k} k_{k}$. Then, noting that the enthalpy of the 1iquid, evaluated at the bubble interface, is given by $\sum_{k} h_{k} \Omega_{k}=h_{m}$, where $h_{m}$ is the monomer enthalpy (see the previous footnote; $\Omega_{k}=0$ for all $\mathrm{k} \neq \mathrm{m}$ ), and that $h_{\mathrm{v}}(\mathrm{x})-\mathrm{h}_{\mathrm{m}}(\mathrm{x})=\mathcal{L}_{\mathrm{m}}(\mathrm{x})$, where $\mathcal{L}_{\mathrm{m}}(\mathrm{x})>0$ is the latent heat of vaporization of the liquid monomer, and using Eqs. (2.3), (2.6), (4.2), (4.5) and (4.9), the liquid-phase equation for conservation of energy becomes

\footnotetext{
* The bubble interface is defined as a region in which the fluid properties differ appreciably from their local average values. This definttion applies especially for the average local molecular weight $W$ of the liquid; near the bubble $W$ is assumed very nearly equal to (but st111 greater than) the monomer molecular welght.
} 


$$
\begin{aligned}
{\left[\rho_{f} c_{p} u+\rho_{f_{k}} c_{p k} Y_{k} U_{k}\right] \frac{d T}{d x}+\rho_{f} u \frac{d}{d x}\left(\frac{u^{2}}{2}\right)=\frac{d}{d x}\left(\lambda \frac{d T}{d x}\right)-\sum_{k} h_{k} w_{k}+\frac{d}{d x}\left(\frac{4}{3} \mu u \frac{d u}{d x}\right) } \\
+4 \pi \mu J^{2} \pi_{3}-\left(L_{m}-\frac{u^{2}}{2}\right)\left[4 \pi \rho_{v} K_{1}+\frac{4 \pi}{3} \frac{d \rho_{v}}{d x} J \pi_{4}\right] \\
-\frac{J^{2}}{2}\left[4 \pi \rho_{v} K_{3}+\frac{4 \pi}{3} \frac{d \rho_{v}}{d x} J \pi_{6}\right]-\left(c \frac{d T}{d x}\right) \frac{4}{3} \pi \rho_{v} \pi_{4^{\circ}}
\end{aligned}
$$

The first three terms on the right-hand side are familiar, and describe the effects of thermal diffusion, chemical reaction and the viscous-stress work, respectively. The fourth term represents the addition of energy to the liquid through bubble friction, while the last term describes the convective bubbleenergy flux. The sum of the terms containing $\mathrm{u}^{2}$ and $\mathrm{J}^{2}$ represents the net kinetic energy lost from the liquid for bubble growth: when $d\left(\rho_{v} v\right) / d t=0$ these terms vanish. Finally, the term containing $\mathcal{L}_{\mathrm{m}}$ [note that the factor in square brackets is simply the mass-1oss term of Eqs. (4.6) and (4.10)] represents the net vaporization energy lost from the liquid for bubble growth.

\section{5 Nondimensiona1 Equations}

To assess the importance of the various terms in Eqs. (4.6), (4.10), (4.11) and (4.13) they are nondimensionalized by using $u=u / r, M=n / n_{0}$, $g=\sigma / \sigma_{s}, \Omega=R / R_{o}, \xi=x / L_{s}, \phi=\rho_{f} / \rho_{s}, \phi_{v}=\rho_{v} / \rho_{v s}, \eta=\mu / \mu_{s}, \theta=T / T$, $\gamma=c_{p} / c_{p s}, h=h / c_{p s} T_{s}, x=\lambda / \lambda_{s}, k=k / k_{s} \quad\left(1 . e_{.}, \dot{R}{ }_{o}=k_{s} / R_{o}\right), \dot{j}=J / J_{s}$ (1.e., $\left.v_{0}=J_{s} R_{0}\right), \ell=\mathcal{L}_{m} / c_{p s} T_{s}, \omega_{k}=\omega_{k} /\left(\rho_{s} r / L_{s}\right), \quad \beta=p / \rho_{s} r^{2}$ and $\pi_{m}=\pi_{m} / n_{0} R_{0}^{m+1}$. Here $r$ is the regression rate, $R_{0}$ is the average value of $R$ in the thermal growth stage, $L_{s}=\alpha_{s} / r$ is the characteristic liquid conduction length and $\sigma_{s}, \rho_{s}, \rho_{v s}, \mu_{s}, T_{s}, c_{p s}$ and $\lambda_{s}$ are, respectively, the characteristic values of the surface tension, the liquid density (mass of liquid per 
unit volume of liquid), the bubble-vapor density, the dynamic viscosity, the liquid temperature, the specific heat and the thermal conductivity, evaluated at the surface. Comparison to Eqs. (2.3) and (2.6) shows that $J_{s}=\sigma_{s} / 2 \mu_{s} L_{s}$ and $K_{s}=(6 / \pi) \alpha_{s} \Lambda_{s}^{2}$, where $\Lambda_{s}$ is the value of the Jakob number evaluated at the surface.

The nondimensionalization of Eqs. $(4.6),(4.8),(4.11),(4.13)$ and (3.1) according to this prescription produces the following nondimensional groups as parameters in the equations:

$$
\begin{aligned}
& \Gamma_{1}=3\left(\rho_{\mathrm{vs}} / \rho_{\mathrm{s}}\right)\left(\mathrm{L}_{\mathrm{s}} / \mathrm{R}_{\mathrm{o}}\right)\left(\AA_{\mathrm{o}} / \mathrm{r}\right)\left(\mathrm{n}_{\mathrm{o}} \mathrm{R}_{\mathrm{o}}\right) \mathrm{v}_{\mathrm{o}}, \\
& \Gamma_{2}=(1 / 3)\left(\mathrm{R}_{\mathrm{o}} / \mathrm{L}_{\mathrm{s}}\right)\left(\mathrm{v}_{\mathrm{o}} / \mathrm{R}_{\mathrm{o}}\right), \\
& \Gamma_{3}=3\left(\mathrm{v}_{\mathrm{o}} / \mathrm{r}\right)\left(\mathrm{L}_{\mathrm{s}} / \mathrm{R}_{0}\right)^{2}\left(\mathrm{n}_{\mathrm{o}} \mathrm{R}_{0}\right) \mathrm{v}_{\mathrm{o}}, \\
& \Gamma_{4}=\mathrm{v}_{\mathrm{o}} / \mathrm{r}, \\
& \Gamma_{5}=\mathrm{r}^{2} / \mathrm{c}_{\mathrm{ps}} \mathrm{T}_{\mathrm{s}},
\end{aligned}
$$

and

$$
\operatorname{Re}=\mathrm{L}_{s} \mathrm{r} / \nu_{\mathrm{s}}=\operatorname{Pr}^{-1}
$$

Here $\Gamma_{1}$ represents the characterist1c magnitude of the mass loss to the bubbles for radial growth [see, e.g., the first term on the right-hand s1de of Eq. (4.6)] while $\Gamma_{2}$ is the ratio of the characteristic magnitudes of the 
second and first terms on the right-hand side of Eq. (4.6); it may be anticipated that $\Gamma_{2} \ll O(1)$, since the translational velocity is generally smaller than the bubble growth rate. The parameter $\Gamma_{3}$ represents the ratio of the drag-force term [the first term on the rhs of Eq. (4.10)] and the shear-force term [the last term on the 1hs]. The ratio of the characteristic bubble velocity and the regression rate is given by $\Gamma_{4}$, which appears in the momentum and energy equations. The quantity $\Gamma_{5}$, which appears in the energy equation [Eq. (4.13)], is the ratio of the kinetic energy of regression to the avai1able thermal energy near the surface, and is generally very small. The parameter $\operatorname{Re}$ is the Reynolds number, and multiplies the convection and pressure-gradient terms in Eq. (4.10). Since $L_{s}=\alpha_{s} / r$, the Reynolds number is the inverse of the Prandtl number.

Reasonable physical estimates for the parameters defined by Eqs. (4.14) to (4.19) are obtalned for PMMA by putting $\lambda_{\mathrm{s}} \sim 10^{-3} \mathrm{cal} / \mathrm{cm}^{-\mathrm{s}}{ }^{\circ}{ }^{\circ} \mathrm{K}$ [29], $\rho_{\mathrm{s}} \sim 1 \mathrm{~g} / \mathrm{cm}^{3}, \quad c_{p s} \sim 1 \mathrm{cal} / \mathrm{g}^{\circ}{ }^{\circ} \mathrm{K}, \mathrm{T}_{\mathrm{s}} \sim 5 \times 10^{2}{ }^{\circ} \mathrm{K}, \mathrm{n}_{\mathrm{o}} \mathrm{R}_{\mathrm{o}} \sim 10^{3}$ bubbles $/ \mathrm{cm}^{3}$, $\mathrm{V}_{\mathrm{o}} \sim 10^{-5} \mathrm{~cm}^{3}, \mathrm{r} \sim 10^{-2} \mathrm{~cm} / \mathrm{s}[5], \rho_{\mathrm{vs}} \sim 10^{-3} \mathrm{~g} / \mathrm{cm}^{3}, \nu_{\mathrm{s}} \sim 10 \mathrm{~cm}^{2} / \mathrm{s}$ and $\sigma_{s} \sim 20$ dyne/cm. Therefore, the characteristic conduction length is $\mathrm{L}_{\mathrm{S}}=\alpha_{\mathrm{s}} / \mathrm{r} \sim 1 \mathrm{~cm}$, the characteristic bubble translational velocity is $v_{0}=J_{s} R_{0}=\sigma_{S} R_{0} /\left(2 \mu_{s} L_{s}\right) \sim 10^{-2} \mathrm{~cm} / \mathrm{s}$ and the characterlstic bubble growth rate is $\dot{R}_{0}=K_{s} / R_{0}=(6 / \pi) \alpha_{s} \Lambda_{s}^{2} / R_{0} \sim 10^{-1} \Lambda_{s}^{2} \mathrm{~cm} / \mathrm{s}$; assuming $\Lambda_{s} \lesssim 0$ (1) [which, from the integrated version of $\mathrm{Eq} \cdot(2.5)$, indicates that in $t \sim 10$ seconds the bubble grows from $\mathrm{R}=0$ to $\mathrm{R} \sim 10^{-2} \mathrm{~cm}$ ] gives $\dot{\mathrm{R}}_{\mathrm{o}} \lesssim 10^{-1} \mathrm{~cm} / \mathrm{s}$. Consequent $1 \mathrm{y}$, $\Gamma_{1} \sim 0\left(10^{-1}\right), \Gamma_{2} \geq 0\left(10^{-3}\right), \Gamma_{3} \geqslant 0\left(10^{2}\right), \Gamma_{4} \sim 0(10), \Gamma_{5} \sim 0\left(10^{-9}\right)$ and $\operatorname{Re} \sim O\left(10^{-4}\right)$. With these estimates the equations for conservation of mass, momentum, species and energy in the melt reduce to 


$$
\begin{aligned}
& \mathrm{d} \frac{(\phi u)}{\mathrm{d} \xi}=-\Delta, \\
& \frac{\mathrm{d}}{\mathrm{d} \xi}\left(\eta \frac{\mathrm{d} u}{\mathrm{~d} \xi}\right)=-r, \\
& \frac{\mathrm{d}}{\mathrm{d} \xi}\left[\phi \mathrm{Y}_{k}\left(u+U_{k}\right)\right]=\omega_{k}-\Omega_{k} \Delta, \quad k=1, \ldots, M
\end{aligned}
$$

and

$$
\phi\left[u+\sum_{k} \gamma_{k} Y_{k} U_{k}\right] \frac{d \theta}{d \xi}=\frac{d}{d \xi}\left(x \frac{d \theta}{d \xi}\right)-\sum_{k} h_{k} \omega_{k}-\ell \Delta,
$$

respectively*, where

$$
\Delta(\xi) \equiv \Gamma_{1}\left[\phi_{v}(\xi) K(\xi) \pi_{1}(\xi)\right]
$$

and

$$
\Gamma(\xi) \equiv \frac{3}{4} \Gamma_{3}\left[n(\xi) \dot{\delta}(\xi) \pi_{2}(\xi)\right]
$$

The terms containing $\Delta$ in Eqs. $(4.20)$ and $(4.22)$ and $\Gamma$ in Eq. $(4.21)$ represent, respectively, the effect of the mass loss from the liquid for radial bubble growth on mass and specles conservation, and the effect of the overall bubble drag force on momentum conservation. The term containing $\Delta$ in Eq. (4.23) represents the loss of vaporization enthalpy from the melt to the bubbles, by virtue of the mass flux across the interface.

\footnotetext{
* The nondimensional form of Eq. (3.1), for the bubble distribution function $n$ is

$$
\frac{\partial(u \dot{\Omega})}{\partial n}+\Gamma_{2} \frac{\partial(n v)}{\partial \xi}=0
$$


In this case a solution for the regression rate is obtained from Eqs. (4.20) to (4.23) by assuming that the mass fractions of the heavy components in the molten liquid remain very nearly constant during pyrolysis. Therefore the mass fractions of the lighter components of degradation must always be very smal1. Under this assumption the Individual clusters of monomer that are formed during degradation must immediately nucleate monomer bubbles, since the nucleated bubbles and their interfaces do not belong to the liquid. As a result, the mass fractions of the light components in the liquid can be very small even though the degradation reactions are proceeding rapidly. This assumption is supported by recent measurements of molecular weight distributions in PMMA samples subjected to an incident radiative heat flux [6].

Therefore, the one-step irreversible reaction $P \rightarrow M$ (polymer $\rightarrow$ monomer) is considered, for which the reaction term [see, e.g., Eqs. (4.11) and (4.13)] is given by $w_{p}=-w_{m}=-A Y_{p}^{m} \exp [-E / Q T]$, where the activation energy, $E$, is much larger than the molar enthalpy, $\mathbb{Q} \mathrm{T}, 1 . \mathrm{e} ., \mathrm{E} / \mathbb{Q} \mathrm{T} \gg 0(1)$. The polymer mass flux into the bubbles, $\Omega_{p}$, is negligible compared with the monomer flux (see Fig. 2), so that $\Omega_{\mathrm{m}}=1-\Omega_{\mathrm{p}} \simeq 1$. In addition, the diffusion velocities in the liquid polymer are assumed negligible and the thermal conductivity of the liquid is assumed constant. In what follows it is useful to introduce the temperature, $\theta$, as the new independent variable. With this definition the inner chemical-reaction/bubble-formation zone is defined by the closeness of $\theta$ to the surface temperature $(\theta=1)$, and not by the physical proximity of the reaction zone to the surface, $\xi=0$. Thus, putting $p=d \theta / d \xi$ into Eqs. $(4.20),(4.21),(4.22)$ (for the polymer only, since $Y_{m}+Y_{p}=1$ ) and $(4.23)$, 
and using $\mathrm{d} / \mathrm{d} \xi=\mathrm{pd} / \mathrm{d} \theta$ (in addition to the previous assumptions), one obtains

$$
\begin{array}{ll}
\text { mass : } & p \frac{d(\phi u)}{d \theta}=-\Delta, \\
\text { momentum: } & p \frac{d}{d \theta}\left(p \eta \frac{d u}{d \theta}\right)=-\Gamma, \\
\text { species: } & p \frac{d}{d \theta}\left(\phi u Y_{p}\right)=-D_{Y_{p}^{m}}^{m} B(1-1 / \theta)
\end{array}
$$

and

energy: $\quad \phi u p=p \frac{d p}{d \theta}-\Delta h D Y_{p}^{m} e^{\beta(1-1 / \theta)}-\ell \Delta$,

respectively. Here $D=\left(\lambda_{s} / \rho_{s} c_{p s} r^{2}\right)\left(A / \rho_{s}\right) \exp \left[-E / R T_{s}\right]$ is the Damkohler number, the ratio of the characteristic convection (residence) time, $t_{c}=\lambda_{s} / \rho_{s} c_{p s} r^{2}$, to the characteristic chemical reaction time, $t_{r}=\left[\left(A / \rho_{S}\right) \exp \left[-E / Q T_{S}\right]\right]^{-1}, B=E / R T_{S}$ is the nondimensional activation energy and $\Delta h=h_{m}-h_{p}$ is the enthalpy difference for the (endothermic) degradation reaction $P \rightarrow M$. The boundary conditions for Eqs. (5.1)-(5.4) are

$$
\left.\begin{array}{l}
\text { 1) } p=0, \phi=1, u=1, Y_{p}=1 \text { when } \theta=\theta_{\infty}, \\
\text { 11) } p=p_{s}, Y_{p}=Y_{p s} \text { when } \theta=1,
\end{array}\right\}
$$

where $p_{S}$ and $Y_{p s}$ are surface values. Note that the bubble number distribution function, n, enters Eqs. (5.1)-(5.4) through the inhomogeneous terms, $\Delta$ and $\Gamma$. 
Expressions for the regression rate, $r$, the fluid velocity, $\boldsymbol{u}$, and the volume fraction, $\phi=\rho_{\mathrm{f}} / \rho_{\mathrm{s}}$, are now derived from Eqs. (5.1)-(5.5) by using the method of matched asymptotic expansions. The largeness of the nondimensional activation energy, $\beta$, is utilized to develop expressions for $p, \phi$, and $Y_{p}$ in an inner chemical-reaction/bubble-formation zone, where $1-\theta \ll 0(1)$, and in an outer heat-up zone, where $\beta(1-\theta) \rightarrow \infty$ and the rates of chemical reaction and bubble formation are negligible.

In the outer zone $\Delta \rightarrow 0, \exp [\beta(1-1 / \theta)] \rightarrow 0$ and $\Gamma \rightarrow 0$. The appropriate lowest-order solutions of Eqs. (5.1) and (5.3) are $\phi=1, \boldsymbol{u}=1$ and $\mathrm{Y}_{\mathrm{p}}=1$. The energy equation becomes $d p / d \theta=1$, to which the solution is $p=\theta-\theta_{\infty}$.

In the Inner zone the variables $Y_{p}=1-T / \beta+\ldots$ and $\theta=1-\theta / \beta+\ldots$ are introduced, consistent with the assumption that $\mathrm{Y}_{\mathrm{p}}$ in the melt is very close to unity and that the temperature is close to its surface value. Therefore in the lowest order Eqs. (5.1)-(5.4) reduce to

mass :

$$
\mathrm{p} \frac{\mathrm{d}(\phi u)}{\mathrm{d} \theta}=\frac{\Delta}{\beta}
$$

momentum:

$$
p \frac{d}{d \theta}\left[p \eta \frac{d u}{d \theta}\right]=-\frac{\Gamma}{\beta^{2}},
$$

species (polymer): $\quad$ p $\frac{d(\phi u)}{d \theta}=\frac{D}{\beta} e^{-\theta}$

and

energy:

$$
\mathrm{p} \frac{\mathrm{dp}}{\mathrm{d} \theta}=-\Delta h_{\mathrm{s}} \frac{\mathscr{D}}{\beta} \mathrm{e}^{-\theta}-\ell_{\mathrm{s}} \frac{\Delta}{\beta},
$$


each of which is now addressed in turn.

Comparison of Eqs. (5.6) and (5.8) indicates that

$$
\Delta=\infty \mathrm{e}^{-\theta}
$$

Thus, all of the monomer produced by the chemical reaction is subsequently lost to the bubbles. Note that the elimination of $\Delta$ from the conservation equations eliminates, from all of Eqs. (5.6)-(5.9), except Eq. (5.7), the explicit influence of the bubble distribution function, $n$.

Since the shear stress in the melt must vanish at the cold edge of the reaction layer, two integrations of Eq. (5.7) give

$$
u=1-\int_{\infty}^{\theta} \frac{d x}{p(x) n(x)} \int_{\infty}^{x} \frac{\Gamma(s)}{\beta^{2} p(s)} d s
$$

When the bubble distribution is highly disperse the quantity $\Gamma / \beta^{2}$, appearing in the integral, is very small compared with unity. Thus, in the lowest approximation $\boldsymbol{u} \simeq 1$, so that the bubbles produce only a negligibly small deviation of the fluid velocity from the regression rate. This appears to be consistent with the two-phase-flow mass balance $[30], \rho_{B} r=\rho_{s} u+\rho_{v} v$, which leads to $u=1-\left(\rho_{v} v\right) /\left(\rho_{s} r\right)=1+o\left(10^{-3} v / r\right)$.

With the assistance of Eq. $(5: 10)$ and the above result, $u=1$, the linear combination of Eqs. (5.8) and (5.9), integrated once, produces

$$
p=\left(1-\theta_{\infty}\right)+\left(h_{v s}-h_{p s}\right)(1-\phi) .
$$


Here, the constant of integration has been determined by matching to the solution in the heat-up zone [which requires 1 im $p^{\text {(inner) }}=1$ im $p^{\text {(outer) }}=1-\theta_{\infty}$ and $\lim \phi^{\text {(inner) }}=1$ ], while the overall heat-release factor, $\Delta h_{s}+\ell_{s}^{+\rightarrow \infty}=\left(h_{\mathrm{m}}-h_{\mathrm{p}}\right)_{\mathrm{s}}+\left(h_{\mathrm{v}}-h_{\mathrm{m}}\right)_{\mathrm{s}}=h_{\mathrm{vs}}-h_{\mathrm{ps}}$, is simply the difference between the bubble-vapor enthalpy and the undegraded polymer enthalpy, evaluated at the surface temperature. Note that the nondimensional temperature gradient, $p$, increases as the bubble volume fraction, $1-\phi$, increases.

The solution for $p$ in the inner zone is obtained by integrating Eq. (5.9) [after substituting Eq. (5.10) for $\Delta$ ]. The integration constant is determined by matching to the solution in the heat-up zone, as before; thus,

$$
p=\left(1-\theta_{\infty}\right) \sqrt{1+\delta e^{-\theta}}
$$

where

$$
\delta=2 \frac{\left(h_{\mathrm{vs}}-h_{\mathrm{ps}}\right)}{\left(1-\theta_{\infty}\right)^{2}} \frac{d}{\beta} .
$$

The composite expansion for $p$, which is valid to lowest order in both zones, is therefore given by

$$
p=\left(1-\theta_{\infty}\right) \overline{1+\delta e^{-\beta(1-\theta)}}-(1-\theta) .
$$

The solution for the bubble volume fraction, $1-\phi$, is obtained by substituting Eq. (5.13) into Eq. (5.12), viz.,

$$
1-\phi=\frac{\left(1-\theta_{\infty}\right)}{\left(h_{\mathrm{vs}}-h_{\mathrm{ps}}\right)}\left[\sqrt{1+\delta e^{-\beta(1-\theta)}}-1\right] .
$$


Note that since $\theta_{\infty} \leq \theta \leq 1$, the bubble volume fraction is always greater than or equal to zero.

\section{V.1 Regression-Rate Formula}

An expression for the regression rate can be obtalned by evaluating Eq. (5.13) at the surface. Thus, putting $p=p_{S}, \theta=0$, and recalling the definition of $\mathscr{D}$ gives, after rearrangement,

$$
r=\left[\frac{2\left(h_{v s}-h_{p s}\right)}{p_{s}^{2}-\left(1-\theta_{\infty}\right)^{2}}\right]^{1 / 2} \cdot \sqrt{\frac{\lambda_{\infty}}{\rho_{\infty} c_{p \infty}} \frac{A}{\rho_{\infty}} \frac{e^{-E / R T_{s}}}{\left(E / R T_{s}\right)}} .
$$

Note that all of the chemical parameters appear under the square-root symbol. The factor in square brackets represents, essentially, the nondimensional ratio of the net enthalpy flux into an individual bubble to the net thermal energy applied to the melt layer; a proper nondimensionalization should make this factor an $0(1)$ quantity.

To complete Eq. (5.17) an expression is required for the surface temperature gradient in the melt, $p_{s}$. It is not possible to use $\mathrm{Eq} \cdot(5.12)$ for this purpose, because it only applies inside the melt, at least one characteristic bubble radius, $R_{0}$, from the surface. Instead, an energy balance across the interface is considered (see Fig. 3). Assuming negligible in-depth heat absorbtion, the net incident heat flux, $Q$, must equal the sum of the net heat conducted into the bubble/melt mixture plus the net energy flux carried back into the gas by surface vaporization and bubble-vapor transport, viz., 


$$
Q=Q_{s}+\dot{m} \mathcal{H}_{s}
$$

The quantity $\dot{m} \mathbb{H}_{S}$ can be expressed as the sum of contributions from the bubbles and from surface vaporization, viz., $\dot{\mathrm{m}}_{H_{\mathrm{S}}}=\dot{\mathrm{m}}_{\mathrm{B}} \mathrm{h}_{\mathrm{vs}}+\dot{\mathrm{m}}_{\mathrm{v}} \mathcal{L}_{\mathrm{s}}$. Here, $\dot{\mathrm{m}}_{\mathrm{B}}$ is the bubble mass flux and $\dot{\mathrm{m}}_{\mathrm{v}}=\dot{\mathrm{m}}-\dot{\mathrm{m}}_{B}$ is the vaporization mass flux. Since

$$
\begin{aligned}
\dot{\mathrm{m}}_{B} & =\int_{0}^{\infty} \mathrm{n}(0, R) \rho_{\mathrm{vs}} \mathrm{v}_{\mathrm{s}} \mathrm{dR} \\
& =\left(\rho_{s} r\right)\left[\left(\frac{\rho_{\mathrm{vs}}}{\rho_{s}}\right)\left(\frac{v_{0}}{\mathrm{r}}\right)\left(\mathrm{n}_{0} \mathrm{R}_{0}\right) v_{0} \pi_{4}(0)\right]
\end{aligned}
$$

then

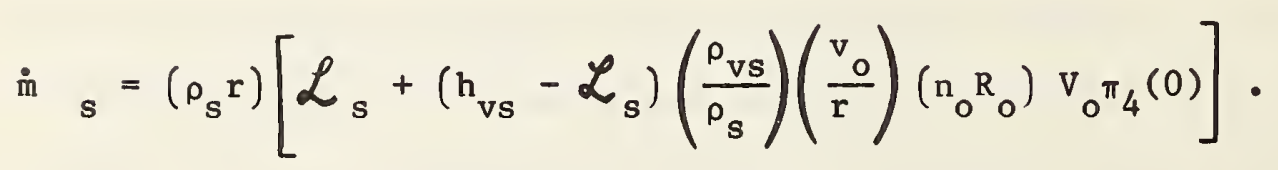

The net conductive heat flux into the mixture is

$$
Q_{s}=\phi_{s} \lambda_{s} \frac{d T}{d x} s+\left(1-\phi_{s}\right) \lambda_{v s} \frac{d T}{d x} s \text {, }
$$

where $\phi_{S}$ is the liquid volume fraction and the second term on the right-hand side represents the heat conducted through the vapor phase. By substituting Eqs. (5.20) and (5.21) into Eq. (5.18), then assuming that $(\mathrm{dT} / \mathrm{dx})_{\mathrm{s}}=$ $\left(\mathrm{dT}_{\mathrm{v}} / \mathrm{dx}\right)_{\mathrm{s}}$, and then solving for $(\mathrm{dT} / \mathrm{dx})_{\mathrm{s}}$ one finds

$$
\lambda_{s}\left(\frac{d T}{d x}\right)_{s}=\frac{Q-\rho_{s} r\left[\mathscr{L}_{s}+\left(h_{v s}-\mathscr{L}_{s}\left(\frac{\rho_{v s}}{\rho_{s}}\right)\left(\frac{v_{0}}{r}\right)\left(n_{0} R_{0}\right) v_{0} \pi_{4}(0)\right]\right.}{\phi_{s}+\frac{\lambda_{v s}}{\lambda_{s}}\left(1-\phi_{s}\right)} .
$$


Equation (5.22) shows that the effect of the bubbles on the temperature gradient in the liquid is the result of two competing processes. The first process, described by the last term in the numerator, decreases $\lambda_{s}(d T / d x)_{s}$, since an increase in the energy carried into the gas by the bubble vapor efflux occurs at the expense of heat conduction into the melt. The second process, described by the denominator of Eq. (5.22), increases $\lambda_{s}(\mathrm{dT} / \mathrm{dx})_{\mathrm{g}}$ by decreasing the amount of avallable liquid in which to conduct heat deeper into the melt. An estimate for the relative importance of these two effects is obtained by forming the nondimensional quotient $\left(1-\phi_{S}\right) /\left(\dot{m}_{B} / \rho_{s} r\right)=$ $\left(\rho_{s} / \rho_{v s}\right)\left(r / v_{0}\right)\left[\pi_{3}(0) / \pi_{4}(0)\right]$, which, for the conditions studied here, is $O\left(10^{2}\right)$. Thus, the primary effect of the bubbles is to increase the temperature gradient in the melt. Note that an increase in the incident heat flux, Q, also increases the temperature gradient.

By nondimensionalizing Eq. (5.22) and using $\lambda_{\mathrm{vs}} / \lambda_{s} \sim 0\left(10^{-1}\right)$, as well as the previous estimates for the two competing processes, one finds

$$
p_{s} \simeq \frac{Q /\left(p_{s} c_{p s} r T_{s}\right)-\ell_{s}}{\phi_{s}} .
$$

Comparison with experiments [5] suggests that the quantity $Q / \mathrm{rT}_{\mathrm{S}}$ decreases with increasing $Q$. Since $\phi_{S}$ also decreases it appears reasonable to assume $\mathrm{p}_{\mathrm{S}} \sim$ constant for the range of parameters considered here. Therefore, the quantity in square brackets in Eq. (5.17) increases as the incident heat flux, the void fraction and the surface temperature all increase. The magnitude of this increase, however, is small in comparison with that of the Arrhenius reaction-rate factor [see Eq. $(5.17)]$. 
The only other quantitative steady-state regression-rate calculations that can be compared with the calculations of this study are those of Lengelle [1]. Direct comparisons, even here, are difficult, because the underlying physical processes modeled in the two studies are completely different. In [1], the regression rate is obtained as a balance between the surface heating rate, the rate of heat removal to the interior of the solid, and the rate at which the polymer degrades to monomer through the one-step reaction $\mathrm{P} \rightarrow \mathrm{M}$. This reaction proceeds fastest at the surface, where the temperature is highest. Consequently, the polymer mass fraction there must be very small $\left(Y_{p s} \ll 1\right)$, while the monomer surface mass fraction is very close to unity. However, according to the discussion in the Introduction, such a formulation is inconsistent with thermodynamic considerations: since the monomer superheat limit is on $1 \mathrm{y} 100^{\circ} \mathrm{C}$, surface temperatures significantly greater than this cannot possibly be achieved without spontaneous phase changes [solid $\rightarrow$ liquid + vapor], due to homogeneous nucleation processes and the associated boiling phenomena. Thus, the original unheated solid polymer must melt or liquify in such a way that the superheat limit of the degradation products (monomer) can be exceeded. In contrast to Lengelle's calculations, the calculations of this study suggest that the regression rate can be obtained as a balance between the surface heating rate, the rate of heat removal into the interior of the condensed phase, and the rate at which monomer is lost from the polymer for bubble formation. The remaining liquid, most of which is original polymer, can then be heated to temperatures much higher than the superheat limit of the liquid monomer. This result appears to be consistent with thermodynamic considerations and experimental observations [5]. 
In the notation of this study the regression-rate formula derived in [1], for PMMA, is given by

$r_{L}=\left[-\left(\Delta h_{s}+1-\theta_{\infty}\right) \ln Y_{p s}-\Delta h_{s}\left(1-Y_{p s}\right)\right]^{-1 / 2} \sqrt{\frac{\lambda_{\infty}}{\rho_{\infty} c_{p \infty}} \frac{A}{\rho_{\infty}} \frac{e^{-E / R T}}{\left(E / Q T_{s}\right)}}$.

Note that the factor appearing under the square-root symbol is identical to that in Eq. (5.17), and that the polymer mass fraction must be assumed very sma11 (in contrast to the assumption $Y_{p} \sim 1$ made in Section $V$ ). Forming the quotient of Eqs. $(5.17)$ and $(6.1)$ gives

$\frac{r}{r_{L}}=\left[\frac{2\left(h_{v s}-h_{p s}\right)\left[-\left(\Delta h_{s}+1-\theta_{\infty}\right) 1 n Y_{p s}-\Delta h_{s}\left(1-Y_{p s}\right)\right]}{p_{s}^{2}-\left(1-\theta_{\infty}\right)^{2}}\right] 1 / 2$.

Using $\mathrm{T}_{\mathrm{s}} \sim 600^{\circ} \mathrm{K}, \mathrm{T}_{\infty} \sim 300^{\circ} \mathrm{K},\left(\mathrm{h}_{\mathrm{m}}-\mathrm{h}_{\mathrm{p}}\right)_{\mathrm{s}} \sim 130 \mathrm{cal} / \mathrm{g}[31],\left(\mathrm{h}_{\mathrm{v}}-\mathrm{h}_{\mathrm{p}}\right)_{\mathrm{s}} \sim 230$ $\mathrm{cal} / \mathrm{g}, \mathrm{c}_{\mathrm{ps}} \sim 1 / 2 \mathrm{cal} / \mathrm{g}-{ }^{\circ} \mathrm{K}[29], \mathrm{Y}_{\mathrm{ps}}=0.01$ [1] and $\mathrm{p}_{\mathrm{S}} \sim 1$ gives $\mathrm{r} / \mathrm{r}_{\mathrm{L}} \sim 3$, indicating that regression rates predicted by Eq. (5.17) are generally larger than those predicted by Eq. (6.1).

Perhaps more 1mportant than comparisons of regression-rate formulas is the result expressed by Eq. (5.16) for the vold fraction, 1- $\phi$. In the customary two-phase-flow analyses [30], the vold fraction is treated simply as an additional independent variable, unrelated to the other dependent variables (such as the temperature). By contrast, Eq. (5.16) defines $1-\phi$ in terms of the temperature, $\theta$, and the remaining chemical and thermochemical parameters, $\theta_{\infty}, h_{\text {vs }}-h_{\text {ps }}, \delta$ and $\beta$. Equation (5.16) can be used to calculate average properties of the two-phase mixture as functions of the temperature and the thermochemical parameters, e.g., for any property $\mathrm{P}, \mathrm{P}_{\text {avg }}=\phi \mathrm{P}_{11 \mathrm{q}}+(1-\phi) \mathrm{P}_{\mathrm{Vap}}$. 
It is not possible to make direct comparisons between the theoretical predictions of this study and the experimental measurements of previous researchers [5], since the theory has been developed under the steady-state assumption while the experiments were conducted under transient conditions. As discussed in Sec. III, a steady state can be attalned only for very large heating times. In this limit, qualitative agreement between the predictions of Eq. (5.17) and the experimental measurements is found; the regression rate increases as both the incident heat flux, $Q$, and the surface temperature, $T_{\mathbf{s}}$, increase. Likewise, the prediction of Eq. (5.16), that the void fraction, $(1-\phi)$, increases with the temperature of the thermoplastic, coincides with one's intultive expectation; the higher the temperature of the medium, the larger the number of bubbles per unit volume that may nucleate. 
pre-exponential factor

specific heat

nucleation frequency factor, see Eq. (3.3)

diameter, $\mathrm{D}=2 \mathrm{R}$

Damkøhler number, $\mathscr{O}=\left(\alpha_{s} / \mathrm{r}^{2}\right)\left(\mathrm{A} / \rho_{s}\right) e^{-E / Q \mathrm{~T}_{s}}$

Eøtvos number, $E_{0}=\rho_{0} g D_{0}^{2} / \sigma_{0}$

force; number of liquid molecules per unit volume

gravitational constant

nondimensional surface tension, $g=\sigma / \sigma_{s}$

enthalpy of polymer melt, $h=h^{(0)}+c_{p}\left(T-T_{0}\right)=\sum_{k} h_{k} Y_{k}$

enthalpy of component $k, h_{k}=h_{k}^{(0)}+c_{p k}\left(T-T_{0}\right)$

vapor-phase enthalpy, $h_{v}=h_{v}^{(0)}+c_{p v}\left(T-T_{0}\right)$

nondimensional enthalpy, $h=\mathrm{h} / \mathrm{c}_{\mathrm{ps}} \mathrm{T}_{\mathrm{s}}$

overall surface enthalpy

nondimensional value of $\mathrm{J}$ [see Section IV.5]

spatially-dependent component of bubble velocity, $J=1 /(2 \mu)\left[\frac{-d \sigma}{d T}\right] \frac{d T}{d x}$

Boltzmann constant, $\mathrm{k}=1.38054 \mathrm{erg} /{ }^{\circ} \mathrm{K}$

spatially-dependent component of bubble growth rate,

$K=(6 / \pi) \alpha\left(\rho / \rho_{v}\right)^{2}\left(c_{p} \Delta T / \mathcal{L}\right)^{2}$

nondimensional vaporization enthalpy, $\ell=\mathcal{L} / \mathrm{c}_{\mathrm{ps}} \mathrm{T}_{\mathrm{s}}$

vaporization enthalpy

characteristic conduction length, $L=\lambda / \rho c_{p} r$

mass flux

Morton number, $M=g_{\mu}{ }^{4} / \rho \sigma^{3}$

number distribution function 
nondimensional number distribution function, $M=n / n_{0}$ bubble number density, $N=\int_{0}^{\infty} n d R$

dynamic pressure

nondimensional temperature gradient, $p=d \theta / d \xi$

nondimensional pressure, $\theta=p / \rho_{s} r^{2}$

Prandt 1 number, $\operatorname{Pr}=\nu / \alpha$

heat flux, $q=-\lambda \frac{d T}{d x}+\rho \underset{k}{\sum} h_{k} U_{k} Y_{k}$

incident heat flux

regression rate

nondimensional bubble radius, $\boldsymbol{A}=R / R_{0}$

bubble radius

ideal gas constant

bubble radial growth rate

Reynolds number, $\operatorname{Re}=2 \mathrm{Rv} / \mathrm{v}$

time

temperature

superheat, $\Delta \mathrm{T}=\mathrm{T}-\mathrm{T}_{\mathrm{V}}$

velocity of polymer melt

nondimensional melt velocity, $u=u / r$

diffusion velocity of species $k$ in melt

bubble translational velocity, $v=\frac{R}{2 \mu}-\left[\frac{d \sigma}{d T}\right] \frac{d T}{d x}$, see Eq. (2.3)

bubble volume, $V=\frac{4}{3} \pi R^{3}$

rate of creation of component $k$ in melt

work of nucleus formation, $W=\frac{4}{3} \pi \sigma R^{2}=G R^{2}$

spatial coordinate

mass-fraction of species $k$ in melt

modified spatial coordinate, see Eq. (3.5) 
thermal diffusivity, $\alpha=\lambda / \rho c_{p}$ nondimensional activation energy, $\beta=E / Q T_{S}$ nondimensional spectfic heat of species $k$ in melt, $\gamma_{k}=c_{p k} / c_{p k s}$ drag-force term, defined by Eq. (4.25)

nondimensional parameters defined by Eqs. $(4.14)-(4.18), 1=1, \ldots 5$ nondimensional overall heat-release factor, see Eq. (5.14) mass-sink term, defined by Eq. (4.24)

nondimensional melt viscosity, $\eta=\mu / \mu_{s}$ nondimensional melt temperature, $\theta=\mathrm{T} / \mathrm{T}_{\mathrm{S}}$ stretched value of $\theta, \theta=\beta(1-\theta)$

nondimensional value of $K, k=K / K_{8}$ thermal conductivity

Jakob number, $\Lambda=\left(\rho / \rho_{v}\right)\left(c_{p} \Delta T / \mathscr{L}\right)$, see Eq. (2.6)

melt viscosity

melt kinematic viscosity

nondimensional spatial coordinate, $\xi=\mathrm{x} / \mathrm{L}_{\mathrm{s}}$

nondimensional value of $\pi_{m}, \pi_{m}=\pi_{m} / n_{0} R_{0}^{m+1}$

$m^{\text {th }}$ moment of bubble distribution function, $\Pi_{m}=\int_{0}^{\infty} n R^{m} d R$ density (mass per unit volume of material)

fluid density (mass per unit volume of space)

surface tension or surface free energy

shear stress, $\tau_{\mathrm{xx}}=-\frac{4}{3} \mu \frac{\mathrm{du}}{\mathrm{dx}}$, see $\mathrm{Eq} \cdot(4.8)$

density ratio or liquid volume fraction, $\phi=\rho_{f} / \rho_{s}$, see Eq. (4.4) vapor-phase density ratio, $\phi_{\mathrm{v}}=\rho_{\mathrm{v}} / \rho_{\mathrm{vs}}$ nondimensional thermal conductivity, $x=\lambda / \lambda_{s}$ nondimensional rate of creation of species $k$ in melt, $\omega_{k}=\frac{\omega_{k}{ }^{L} s}{\rho_{s} r}$ mass-flux fraction of species $k$ into bubbles 
Subscripts

b

B

g

I

o

s

$\mathrm{T}$

v

$\infty$

Superscripts bolling or saturation condition

bubbles

gas phase

initial bubble growth stage

reference condition

surface

therma1 bubble growth stage

vapor

ambient condition

monomer cluster 


\section{REFERENCES}

1. Lengelle, G., AIAA J. 8:1987 (1970).

2. Rabinovitch, B., Tenth Symposium (International) on Combustion, The Combustion Institute, 1965, pp. 1395-1404.

3. Houser, T.J., J. Chem. Phys. 45:1031 (1966).

4. Kumar, R.N. and Stickler, D.B., Thirteenth Symposium (International) on Combustion, The Combustion Institute, 1971, pp. 1059-1072.

5. Kashiwag1, T. and Ohlemiller, T., Nineteenth Symposium (International) on Combustion, The Combustion Institute, 1982, pp. 815-823.

6. Brown, J.E., Symposium on the Chemistry of Combustion Processes, Div. of Industrial and Englneering Chemistry, ACS Meeting (March 1983).

7. Clift, R., Grace, J.R. and Weber, M.E., Bubbles, Drops and Particles Academic, NY, 1978.

8. Harper, J.F., Adv. Appl. Mech. 12:59 (1972).

9. Young, N.0., Goldstein, J.S. and Block, M.J., J. Flu1d Mech. 6:350 (1959).

10. Bankoff, S.G., Adv. Chem. Eng. 6:1 (1966).

11. Plesset, M.S., in Proceedings of the Symposium on Cavitation in Real Liquids, (R. Davies, Ed.) Warren, MI, 1962, Pp. 1-18.

12. Plesset, M.S. and Prosperetti, A., Ann. Rev. Fluid Mech. 9:145 (1977).

13. Hsieh, D.Y., J. Basic Eng., ASME D 87:991 (1965).

14. Prosperett1, A. and Plesset, M.S., J. Fluid Mech. 85:349 (1978).

15. Barlow, E.J. and Langlols, W.E., IBM J., 329 (1962).

16. Street, J.R., Fricke, A.L. and Re1ss, L.P., Ind. Eng. Chem. Fund. 10:54 (1971).

17. Lasheras, J.C., Yap, L.T. and Dryer, F.L., Twentieth Symposium (International) on Combustion, (to appear).

18. Plesset, M.S. and S. A. Zwick, J. Appl. Phys. 25:493 (1954).

19. G. Birkhoff, R. S. Margulles and W. A. Horning, Phys. Fluids 1:201 (1958).

20. Scriven, L.E., Chem. Engng. Sci. 10:1 (1959).

21. Mikic, B.B., Rohsenow, W.M. and Griffith, P., Int. J. Heat Mass Transfer, 13,657 (1970). 
22. W11l1ams, F.A., E1ghth Symposium (Internationa1) on Combustion, W1lliams and Wilkins Co., Baltimore, 1962, pp. 50-69.

23. Twomey, S., Atmospheric Aerosols Elsevier, Amsterdam, 1977.

24. Dunning, W.J., in Nucleation, (A.C. Zettlemoyer, Ed.) Marcel Dekker, NY, 1969 , pp. 1-67.

25. Feder, J., Russe1, K.C., Lothe, J. and Pound, G.M., Adv. Phys. 15:111 (1966).

26. Cole, R., Adv. Heat Transfer 10:86 (1974).

27. Bernath, L., Ind. Eng. Chem. 44:1310 (1952).

28. Stewart, C.W., J. Poly. Sci. 8:937 (1970).

29. Ray, S.R., Ph.D Thesis, Princeton University, Princeton, NJ, 1980.

30. van Wijngaarden, L., Ann. Rev. Fluid Mech. 4:369 (1972).

31. Seshadri, K. and Williams, F.A., J. Poly. Sci. 16:1755 (1978). 


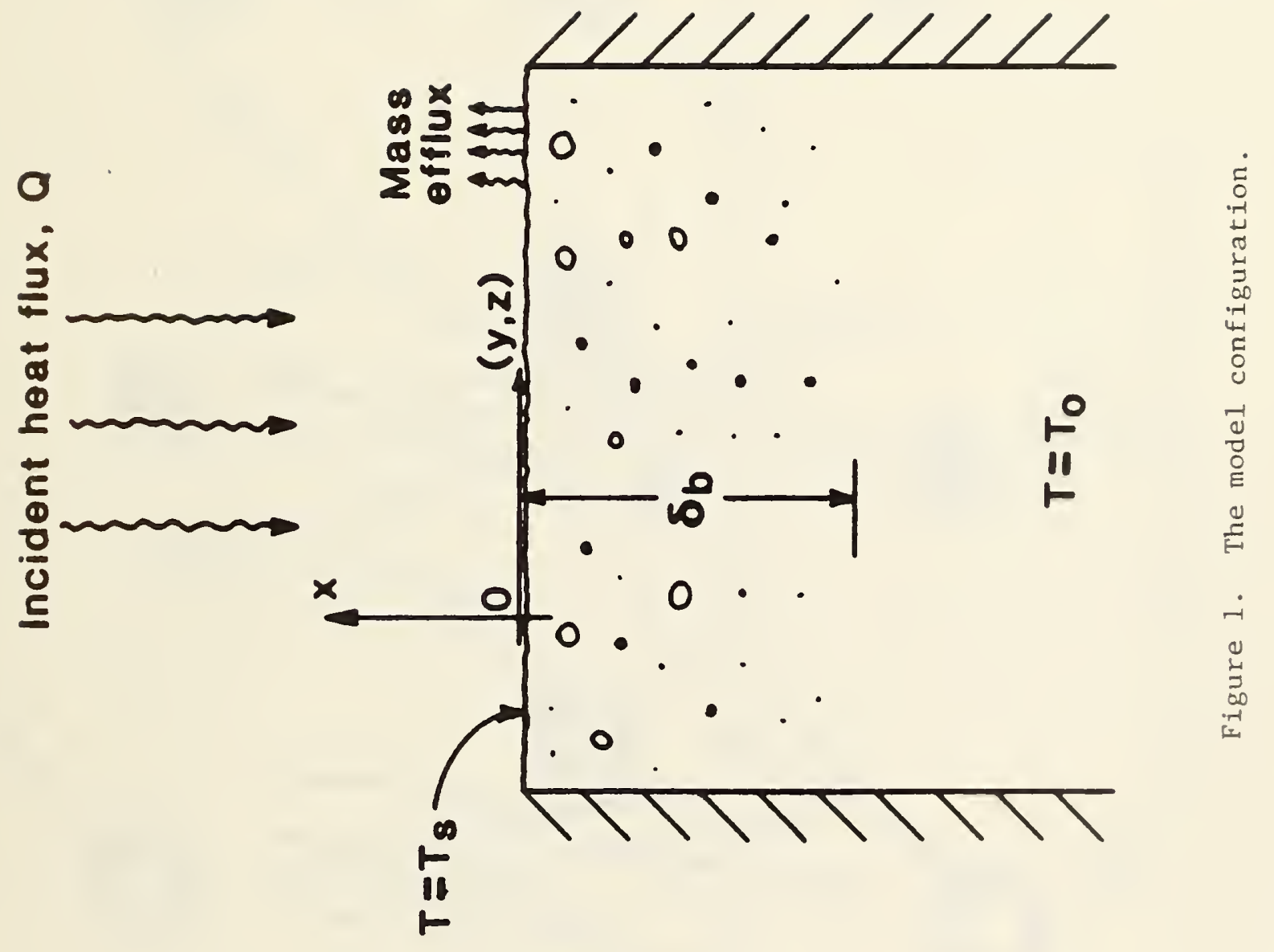


a)

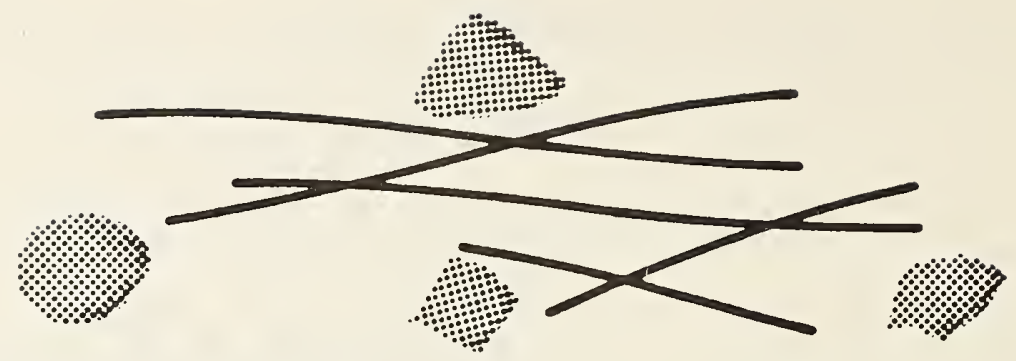

b)
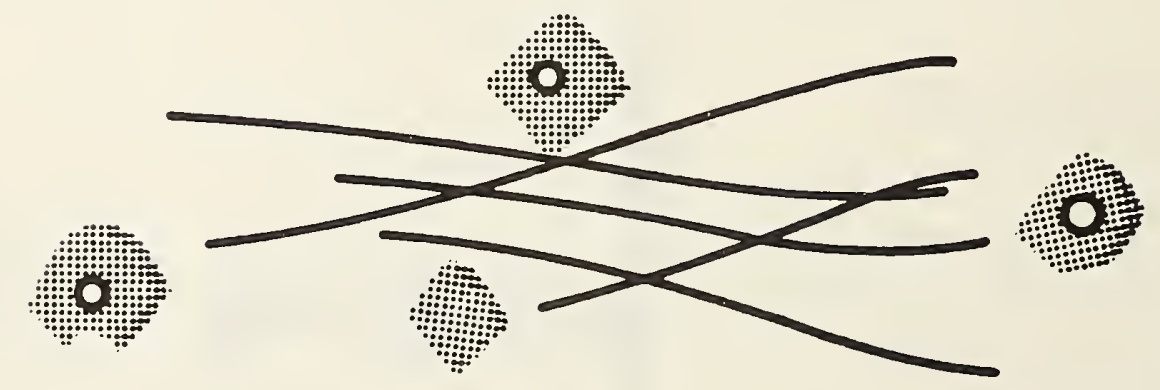

c)
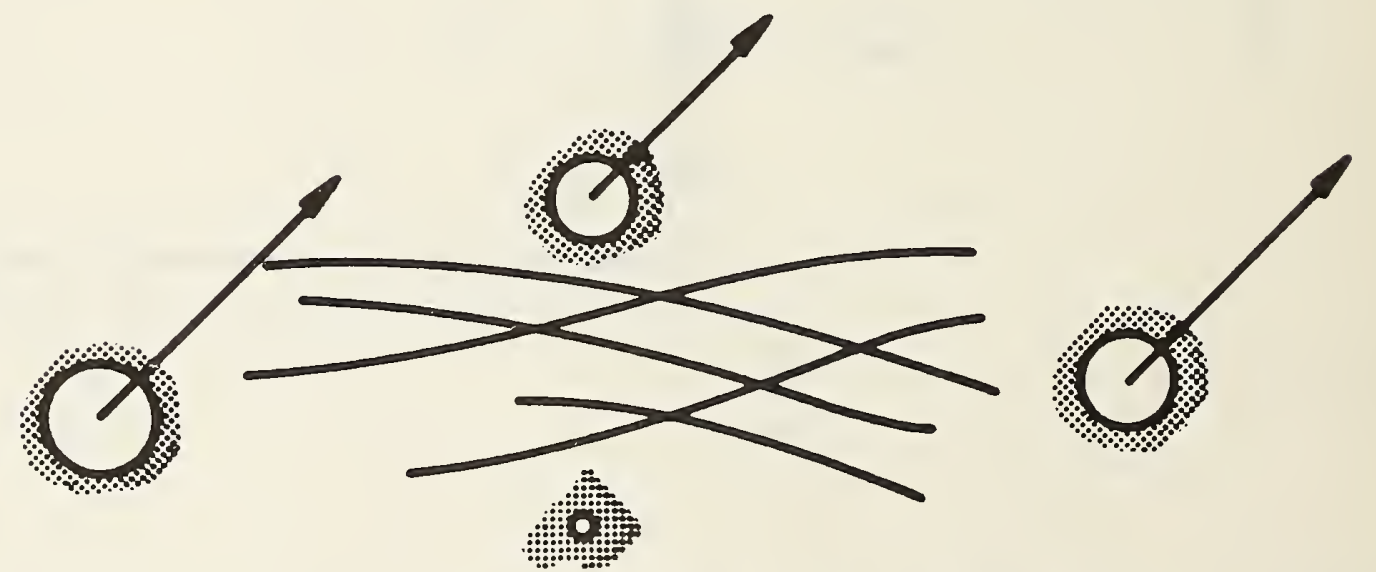

Figure 2. The nucleation and growth of bubbles in the polymer melt. (a) Small clusters of monomer are formed.

(b) The monomer clusters may nucleate small bubbles, which may grow or collapse. (c) The growing bubbles translate in the direction of the local temperature gradient; they are at all times surrounded by a layer of monomer. Bubble growth takes place through vaporization at the interface. 


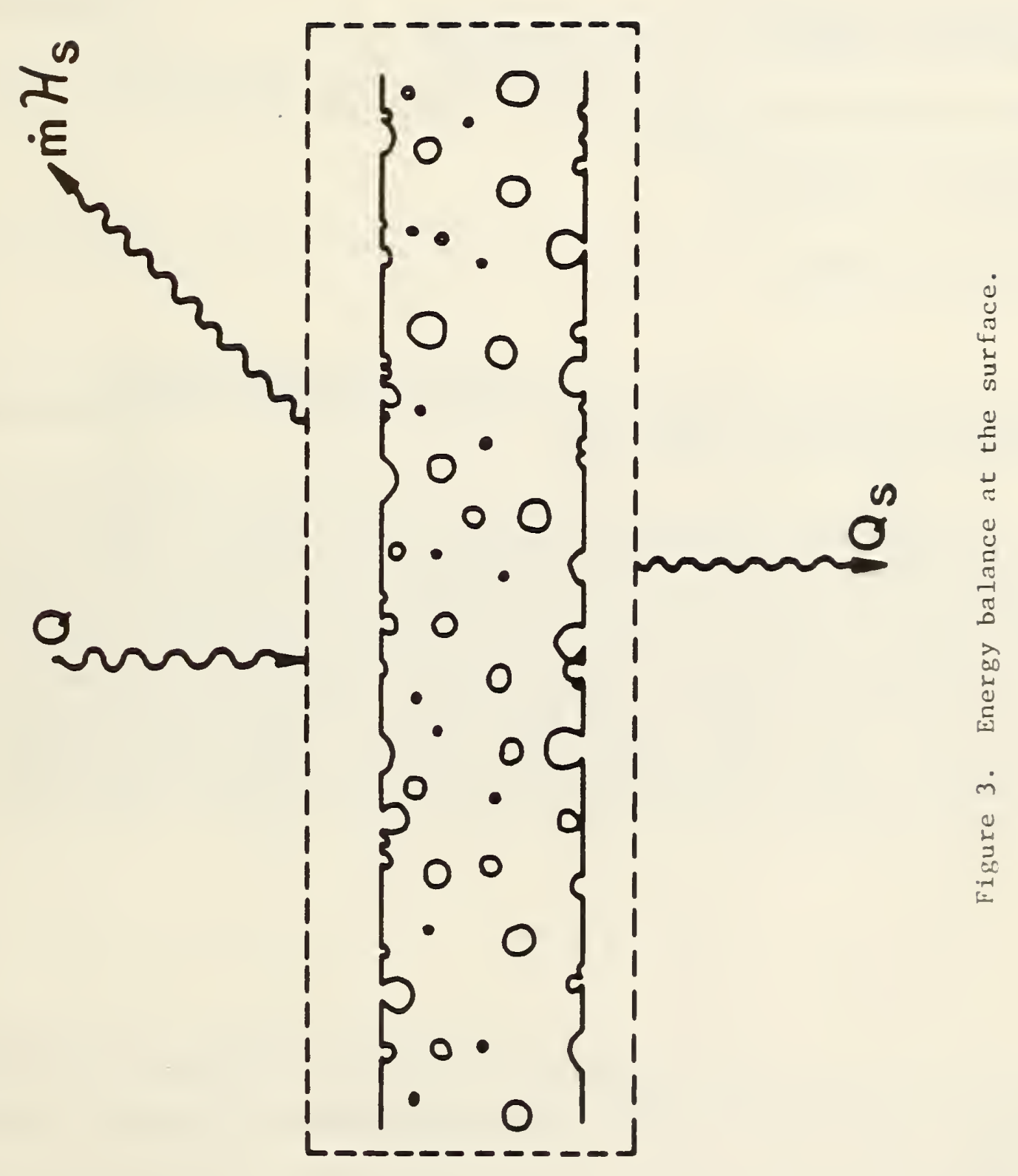


4. TITLE AND SUBTITLE

A Model Describing the Steady-State Pyrolysis of Bubble-Forming Polymers in Response to an Incident Heat Flux

\section{AUTHOR(S)}

Indrek S. Wichman

6. PERFORMING ORGANIZATION (If joint or other than NBS, see instructions)

7. ContracUGrant No.

NATIONAL BUREAU OF STANDARDS

DEPARTMENT OF COMMERCE

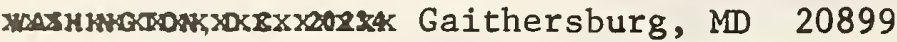

\section{SPONSORING ORGANIZATION NAME AND COMPLETE ADDRESS (Street, City, State, ZIP)}

National Bureau of Standards

Department of Commerce

Washington, D.C. 20234

10. SUPPLEMENTARY NOTES

Document describes a computer program; SF-185, FIPS Software Summary, is attached.

11. ABSTRACT (A 200-word or less factual summary of most significant informotion. If document includes a significant bibliography or literature survey, mention it here)

A theoretical model is developed to describe the in-depth effect of bubbles on the steady-state transport of volatile gases (monomer) from the surface of a polymer subjected to an incident heat flux. In this model the effect of the bubbles on the surrounding (1iquid) polymer is felt through the bubble number distribution function, $n$, which appears in the equations for conservation of mass, momentum, species and energy in the melt. The equation for the evolution of $\mathrm{n}$ includes the effects of bubble growth, convection and nucleation; its derivation requires preliminary study of the growth and motion of an individual bubble in a liquid with a temperature gradient. With these equations, formulas for the mass flux of volatiles from the polymer surface and the bubble void fraction are developed, for the special case of constant polymer mass fraction.

12. KEY WORDS (Six to twelve entries; alphabetical order: capitalize only proper names; and separate key words by semicolons)

Bubbles; convection; Heat Flux; Mathematical Models; Nucleation; Polymers; Steady State

13. AVAILABILITY

X Unlimited

For Official Distribution. Do Not Release to NTIS

Order From Superintendent of Documents, U.S. Government Printing Office, Washington, D.C. 20402.

14. NO, OF PRINTED PAGES 47

15. Price

X Order From National Technical Information Service (NTIS). Springfield, VA, 2216I 

